\title{
Study of physical characteristics of Indian handball players at different level of competition
}

\author{
Vishaw GAURAV ${ }^{1}$, Amandeep SINGH ${ }^{2}$ \\ ${ }^{1}$ Department of Education, Government of Punjab, India. \\ 2 Department of Physical Education (T), Guru Nanak Dev University, Amritsar, India. \\ Address Correspondence to Amandeep Singh, prof_aman@yahoo.com
}

\begin{abstract}
The purpose of the study was to compare the physical characteristics between Indian male handball players at different level of competition. The present study was conducted on a sample of forty eight $(\mathrm{N}=48)$, which includes twenty four each, male inter-school level $\left(\mathrm{N}_{1}=24\right.$, mean \pm SD: age $18.12 \pm 0.80$ years, height $176.83 \pm 5.83 \mathrm{~cm}$, weight $69.04 \pm 6.99 \mathrm{~kg}$, BMI 22.07 \pm 1.89$)$ andinter-college level $\left(\mathrm{N}_{2}=24\right.$, mean $\pm \mathrm{SD}$ : age $20.54 \pm 0.93$ years, height $181.29 \pm 3.44 \mathrm{~cm}$, weight $74.04 \pm 3.89 \mathrm{~kg}$, BMI $22.53 \pm$ 1.30) handball players who participated in inter-school competitions of the schools affiliated to Punjab School Education Board and inter-college competitionsof Guru Nanak Dev University, Amritsar, Punjab, India respectively. All the participants were informed about the aim and methodology of the study and they volunteered to participate in this study. All the participants were assessed for height, weight and selected physical characteristics. The height of the subjects was measured with anthropometric rod to the nearest $0.5 \mathrm{~cm}$. The weight of subjects was measured by using portable weighing machine to the nearest $0.5 \mathrm{~kg}$. The vertical jump test was used to measure explosive power of the legs whereas speed was determined by 30 meters dash. Illinois agility test was used to measure agility and medicine ball put testwas used to determine the shoulder girdle strength. The independent samples t-test was applied to assess the differences between inter-school and inter-college level handball players. The level of significance was set at 0.05 .The results of present study clearly indicated that inter-college level handball players had significantly greater power $(p<0.05)$, speed $(p<0.05)$, strength $(p<0.05)$ and agility $(p<0.05)$ than inter-school level male handball players. The inter-college level male handball players were also found taller and heavier as compared to inter-school level players.
\end{abstract}

Keywords: Physical characteristics, handball, power, speed, strength, agility.

\section{INTRODUCTION}

Team handball is a complex intermittent game, which requires players to have well developed aerobic and anaerobic capacities (1). Successful performance requires explosive power of the legs and arms, sprint velocity and kinesthetic feeling in ball control (8). Team handball originated in the Berlin Physical Education School in 1919 with Professor Carl Schelenz, and became an official Olympic Sport in 1972. Since its beginning team handball has developed into a very popular game in European countries, and is slowly becoming a recognized sport worldwide (9). Handball players requires various technical skills (e.g. shooting, passing and throwing) and physical characteristics (e.g. jumping ability, power, speed and agility) at different level of competition. Previous research has indicated that certain physical characteristics are related to high-level handball performance $(3,7,14)$.
During the game, tasks such as pushing and blocking require high power and strength levels in the limbs and trunk regions $(3,6,13)$. Stronger players with higher body mass have an advantage in handball because the need of the game, such as throwing the ball with power and speed, are met through jumping and physical contact with the opponent (3). Though literature related to physical characteristics of handball players are available, information in Indian context is scanty. To fulfill the lack of literature, the present study was planned. Therefore, the purpose of this study was to compare thephysical characteristics of Indian handball players at different level of competition (i.e. interschool level and inter-college level).

\section{MATERIAL \& METHOD}

A sample of 48 subjects, which includes 24 each, inter-school level $\left(\mathrm{N}_{1}=24\right.$, mean \pm SD: age 18.12 \pm 0.80 years, height $176.83 \pm 5.83 \mathrm{~cm}$, weight $69.04 \pm$ 
$6.99 \mathrm{~kg}, \mathrm{BMI} 22.07 \pm 1.89)$ andinter-college level $\left(\mathrm{N}_{2}=24\right.$, mean \pm SD: age $20.54 \pm 0.93$ years, height $181.29 \pm 3.44 \mathrm{~cm}$, weight $74.04 \pm 3.89 \mathrm{~kg}$, BMI $22.53 \pm$ 1.30) male handball players, was selected for the present study. The purposive sampling technique was used to select the subjects. The inter- school level subjects were selectedfrom different schools affiliated to Punjab School Education Board and inter-college level subjects were selected from different colleges affiliated to Guru Nanak Dev University, Amritsar, Punjab, INDIA.

Height measurements were taken by using the standard anthropometric rod to the nearest $0.5 \mathrm{~cm}$. Full attention was given to make sure that players' body was fully upright and their mandible was parallel to the ground. Taken values recorded in 'cm'. The subject's weight was measured with portable weighing machine to the nearest $0.5 \mathrm{~kg}$. During measurements players were on bare feet and wearing underwear only. Measurements recorded in ' $\mathrm{kg}^{\prime}$. BMI was calculated by the formula of; Body Mass Index $=$ Weight $/$ Height $^{2}$.The vertical jump test was used to measure explosive power of the legs whereas speed was determined by 30 meters dash. Illinois agility test (2) was used to measure agility and medicine ball put test was used to determine the shoulder girdle strength.

\section{Statistical analyses}

Data was analyzed using SPSS Version 16.0 (Statistical Package for the Social Sciences, version
16.0, SPSS Inc, Chicago, IL, USA). Mean values $( \pm S D)$ of Demographic characteristics of inter-school level and inter-college level male handball players are presented. Independent samples t-test was used to test if population means estimated by two independent samples differed significantly.

\section{RESULTS}

Table 1 shows the demographic characteristics of inter-school level and inter-college level male handball players. The mean age of inter-school level players was 18.12years and inter-college level players were 20.54years. The mean height of interschool level players was $176.83 \mathrm{~cm}$ and inter-college level players were $181.29 \mathrm{~cm}$. The mean weight of inter-school level players was $69.04 \mathrm{~kg}$ and intercollege level players were $74.04 \mathrm{~kg}$. The mean BMI value of inter-school level players was 22.07and inter-college level players were 22.53.

Table-2 presents the physical characteristics of inter-school level and inter-college level male handball players. The inter-college level players were found to have significantly better power $(p<0.05)$ when compared to inter-school level players. The inter-college level players also had significantly better speed $(p<0.05)$ and strength $(p<0.05)$ than inter-school level players. Similarly, agility $(p<0.05)$ was significantly greater in intercollege level players as compared to inter-school level players.

Table 1.Demographic characteristics of inter-school level $(\mathrm{N}=24)$ and inter-college level $(\mathrm{N}=24)$ male handball players.

\begin{tabular}{|c|c|c|c|c|c|c|c|c|}
\hline \multirow{2}{*}{ Sports Group } & \multicolumn{2}{|c|}{ Age (yrs) } & \multicolumn{2}{|c|}{ Height $(\mathrm{cm})$} & \multicolumn{2}{|c|}{ Weight (Kg) } & \multicolumn{2}{|c|}{ BMI } \\
\hline & Mean & SD & Mean & $\mathrm{SD}$ & Mean & SD & Mean & SD \\
\hline Inter-School Players & 18.12 & 0.80 & 176.83 & 5.83 & 69.04 & 6.99 & 22.07 & 1.89 \\
\hline Inter-College Players & 20.54 & 0.93 & 181.29 & 3.44 & 74.04 & 3.89 & 22.53 & 1.30 \\
\hline
\end{tabular}

Table 2. Physical characteristics of inter-school level (N=24) and inter-college level (N=24) male handball players.

\begin{tabular}{|c|c|c|c|c|c|c|c|c|}
\hline \multirow[t]{2}{*}{ Variables } & \multicolumn{2}{|c|}{$\begin{array}{l}\text { Inter-School Players } \\
\qquad\left(\mathrm{N}_{1}=24\right)\end{array}$} & \multicolumn{2}{|c|}{$\begin{array}{l}\text { Inter-College Players } \\
\qquad\left(\mathrm{N}_{2}=24\right)\end{array}$} & \multirow{2}{*}{$\begin{array}{c}\text { Mean } \\
\text { Difference }\end{array}$} & \multirow[t]{2}{*}{ SEDM } & \multirow[t]{2}{*}{$\mathrm{t}$} & \multirow{2}{*}{$\mathrm{p}$} \\
\hline & Mean & SD & Mean & $\mathrm{SD}$ & & & & \\
\hline Power $(\mathrm{cm})$ & 42.37 & 4.35 & 47.25 & 5.37 & 4.88 & 1.41 & $3.456^{*}$ & 0.001 \\
\hline Speed (sec) & 5.41 & 0.38 & 4.97 & 0.84 & 0.44 & 0.19 & $2.316^{*}$ & 0.025 \\
\hline Strength (m) & 7.62 & 0.14 & 8.01 & 0.44 & 0.39 & 0.09 & $4.145^{*}$ & 0.000 \\
\hline Agility (sec) & 19.78 & 0.84 & 16.91 & 0.86 & 2.87 & 0.24 & $11.683^{*}$ & 0.000 \\
\hline
\end{tabular}

\section{DISCUSSION}

In the present study physical characteristics of inter-school level and inter-college level male handball players have been evaluated and compared with each other. This study indicates the existence of physical characteristics differences between interschool level and inter-college level male handball players. The demographic characteristics of interschool level and inter-college level male handball players showed that inter-college level players were taller and heavier as compared to inter-school level 
players.A large height and lean body mass are beneficial for performance in handball players (3).In the present study, the mean height and weight in inter-college handball players $(181.29 \pm 3.44 \mathrm{~cm}$ and $74.04 \pm 3.89 \mathrm{~kg}$ respectively) were lesser than in male Serbian U-20 hand ball players $\quad(190.70 \pm 5.23$ $\mathrm{cm}$ and $88.44 \pm 8.98 \mathrm{~kg}$ respectively) reported by Ilic et al. (5), players of China(190.0 $\pm 7.4 \mathrm{~cm}$, and $85.4 \pm 10.0 \mathrm{~kg}$, respectively) and Japan $(185.4 \pm 6.7 \mathrm{~cm}$ and $80.6 \pm 3.9 \mathrm{~kg}$, respectively) reported by Hassan et al.(4).The demographic characteristics of players showed that the Indian inter-school level handball players had significantly higher values of body height $(176.83 \pm 5.83 \mathrm{~cm})$ compared to English $(174.2 \pm 5.4 \mathrm{~cm})$ handball players studied by Hassan et al. (4). It was reported that body height and body mass were important for the performance enhancement of athletes and were considered as basic criterion for their selection in various playing positions in handball game $(10,12)$.The results of present study clearly indicated that inter-college level handball players had significantly greater power, speed, strength and agility than inter-school level handball players.These differences are probably due to the effects of regular physical exercise and vigorous training program in intercollege handball players.These results of present study are supported by Stijn et al.(11).They observed significantly greater power characteristics, i.e. counter-movement jump height, handgrip strength, sprint running speed and aerobic capacity in elite adolescent handball players in comparison with the non-elite players (10). Considering the inter-college players showed better physical characteristics, on average, the inter-college level male handball players were taller and heavier than inter-school level players. The inter-college level male handball players also had higher power, speed, strength and agility when compared to inter-school level male handball players. It is concluded that various physical characteristics has clear impact on the performance of the handball players at different level of competition. This study indicate the need for further research regarding playing position-byplaying position analysis of physical characteristics of handball players including correlations with players' performance.

\section{ACKNOWLEDGEMENTS}

Sincere thanks to physical education teachers \& coaches who extended their enthusiastic cooperation in collecting the necessary data and to all those inter-school level and inter-college level male handball players without whom this research was not possible. We acknowledge the immense help received from the scholars whose articles are cited and included in references of this paper. We are also grateful to authors/editors/publishers of all those articles, journals and books from where the literature for this paper has been reviewed and discussed.

\section{REFERENCES}

1. Delamarce P, Gratas A, Beillot J, Dassonville J, Rochcongar P, Lessard Y. Extent of lactic anaerobic metabolism in handballers. Int J Sports Med. 1987; 8:55-9.

2. Getchell B. Physical Fitness: A Way of Life, 2nd ed. New York: John Wiley and Sons, Inc. 1979.

3. Gorostiaga EM, Granados C, Ibanez J, Izquierdo M. Differences in physical fitness and throwing velocity among elite and amateur male handball players. Int J Sports Med, $2005 ; 26: 225-232$.

4. Hassan AA, Rahaman JA, Cable NT, Reilly T. Anthropometric profile of elite male handball players in Asia. Biology of Sport, 2007; 24(1): 3-12.

5. Ilic V, Macura M, Ranisavljev I. Profile of young elite handball players according to playing positions. RIK, 2011; (39)1: 71-77.

6. Izquierdo M, Häkkinen K, Gonzalez-Badillo JJ, Ibáñez J, Gorostiaga EM. Effects of long term training specificity on maximal strength and power of the upper and lower extremities in athletes from different sports. Eur J Appl Physiol, 2002; 87: 264-271.

7. Lidor R, Falk B, Arnon M, Cohen Y, Segal G, Lander Y. Measurement of talent in team handball: the questionable use of motor and physical tests. J Strength Cond Res, 2005; 19: 318-325.

8. Sibila M. Initial and further selection of children gifted for handball on the basis of some chosen morphological and motor parameters. Handball EHF Periodical, 1997; 1: 7-17.

9. Spori G, Vuleta D, Vuleta DJr, Milanovi D. Fitness profiling in handball: physical and physiological characteristics of elite players. Coll Antropol, 2010; 34 (3): 1009-1014.

10. Srhoj V, Marinovic M, Rogulj N. Position specific morphological characteristics of top-level male handball players. Coll Anthropol, 2002; 1: 219-227.

11. Stijn PJM, Vaeyens R, Vandendriessche J, Vandorpe B, Pion J, Aaron J, Coutts AJ, Lenoir M, Philippaerts RM. A multidisciplinary identification model for youth handball, European Journal of Sport Science, 2011; 11: 355-363.

12. Taborsky F. The body height and top team handball players. EHF web Periodical. 2007, Available on http://activities.eurohandball.com.

13. Wallace MB, Cardinale M. Conditioning for team handball. Strength Cond J, 1997; 19: 7-12.

14. Ziv G, Lidor R. Physical attributes physiological characteristics, on-court performances and nutritional strategies of female and male basketball players. Sports Med, 2009; 39: 547-568. 